\title{
ANTIVIRAL EFFECT OF THE EGYPTIAN BEE VENOM (BV) AND ITS FRACTION (PLA2) ON INFLUENZA VIRUS: IN-VITRO STUDY
}

\author{
By \\ ABIR A. ELFIKY ${ }^{1}$, NORHAN M. ELASMY ${ }^{1}$, WALAA H. SALAMA ${ }^{2}$ \\ AND AYMAN T. A. MORSY ${ }^{3}$
}

Anti-venom Research, (VACSERA), Dokki, Egypt ${ }^{1}$, and Department of Molecular Biology; Genetic Engineering and Biotechnology Division, National Research Centre, Dokki $^{2}$, and Consultant Tropical Medicine and Fever $^{3}$, Ministry of the Interior, Egypt

(*Correspondence: elfikyabir@gmail.com)

\section{Abstract}

Influenza is a viral infection that attacks the respiratory system. For most people, the flu disappears on its own but sometimes the flu and its complications can be deadly. This study established a new trend to treat Influenza virus by using bee venom and its fraction compared with the traditional flu drug. It was proved that bee venom (BV) has an antiviral effect. The bee venom (BV), bee venom phospholipase $A_{2}$ (BV-PLA2) and ribovinal as a control drug were used. The cytotoxicity of the selected compounds was determined using MTT assay. Also, the cytopathic effect was measured after $24,48 \& 72$ hours incubations and determination of gene expression of INF-gamma using SYBR Green. The IC50s of BV, BVPLA2 and ribovinal were $87.8,17.3 \& 137.5 \mu \mathrm{g} / \mathrm{ml}$ after 24 hours incubation, $36.9,9.6 \&$ $24.6 \mu \mathrm{g} / \mathrm{ml}$ after 48 hours incubation, and $9.7,7.45 \& 31.6 \mu \mathrm{g} / \mathrm{ml}$ after 72 hours incubation, respectively. In addition, the cytopathic effect of both $\mathrm{BV}$ and ribovinal was directly proportional to its concentration and incubation time. Whereas, BV-PLA2 showed an increase in cytopathic effect after 48 hours in spite of its concentration in case of direct antiviral effect. However, the indirect antiviral effect for both BV and PLA2 showed the same cytopathic effect in all concentrations and incubation times. So, the gene expression of INF- $\gamma$ was significant increased after 48 hours incubation of either BV or ribovinal in direct and indirect effects. While the INF- $\gamma$ expression was $(14.8 \& 16.4)$ direct and in indirect antiviral effects of BV-PLA2, respectively. These findings revealed the antiviral effect of both bee venom and BV-PLA 2 against influenza virus.

\section{Introduction}

Influenza virus by virus classification is an enveloped the RNA virus composed of five strains of the family of intact mucosal viruses (Chertow and Kindrachuk, 2020). There are two fundamental sorts of flu (influenza) infection; Types A \& B. The flu A \& B infections that routinely spread in individuals (human flu infections) are in charge of the regular influenza scourges annually. The influenza (flu) is different from a cold usually comes on suddenly and can cause mild to severe illness, and at times can lead to death (CDC, 2019). People who have flu often feel some or all of these symptoms: fever or feeling feverish/chills, cough, sore throat, runny or stuffy nose, muscle or body aches, headaches, fatigue (tiredness), some people may have vomiting and diarrhea, though this is more common in children than adults. But, it's important to note that not everyone with flu will have a fever (Sehatzadeh, 2012).

However, the problem of influenza is mainly related to its potential complications, which include: pneumonia, bronchitis, ear infections and CVS \& CNS complications. Specific people are more likely to have influenza complications especially immunocompromised and its incubation period ranged from one to four days (Blut, 2009). During this period, the virus is present and grows in the body before the onset of symptoms. Also, you will not have any symptoms of the flu, but you may have recently been infected by others. A person infected with the virus can infect others before the onset of symptoms one to 
two days and continued to be able to transmit the infection until one week from the onset of symptoms and may be able to transmit infection up to ten days (Carman et $a l, 2019)$. The accessible investigations on the antiviral resistance of flowing influenza strains are rare, so this work embraced an examination of the sequences announced in public gene banks to play out a deliberate investigation of the antiviral resistance markers on both M2 \& NA. Taking all facts together (sequences from 2000 to 2017 were considered), 284 M2 successions and 423 NA arrangements were recovered from three hereditary databases (Toledo-Rueda et al, 2018). Bee venom (BV) contains in any event 18 pharmacologically dynamic parts including melittin (MLT), phospholipase A2 (PLA2), and apamin and so forth. BV is safe for human medicines portion conditionally and demonstrated to have distinctive mending properties including antibacterial, antiparasitic and antiviral properties. In any case, the antiviral properties of BV have not all around examined (Toledo-Rueda, 2018). Consequently, the potential antiviral properties of BV and its part were involved in wide variety of infections. The use of bee venom for such purposes was not been fully established, as it was a must. The effect of bee venom on the allergies removal from hypersensitive individuals is still under investigation. Pure bee venom is not available in quantities; these extracts contain many proteins that have no chemical relationship with proteins found in the pure bee venom (Blank et al, 2017). But, the substances injected by the sting machine are also believed to contain specialized bee proteins (allergen) that cause sensitivity. The allergists preferred to use the entire bee body extract due to its low toxin content.

The present study aimed to through more light on the medical value of antiviral activity of Egyptian bee (Apis mellifica) venom.

\section{Materials and Methods}

Culture medium was removed to a centrifuge tube then the cell layer was rinsed with $0.25 \%(\mathrm{w} / \mathrm{v})$ trypsin $0.52 \mathrm{mM}$ EDTA solution in order to remove all traces of serum contains trypsin inhibitor by the following step: 2.0 to $3.0 \mathrm{ml}$ of Trypsin EDTA solution were added to flask and observe cells under an inverted microscope until cell layer is dispersed (within 5 to 15 minutes) then 6.0 to $8.0 \mathrm{~mL}$ of complete growth medium were added by pipetting after these steps the cell suspension was put into the centrifuge tube with the previous medium cells then the centrifuged at approximately $125 \mathrm{xg}$ for 5 to 10 minutes. The supernatant was discarded in fresh growth medium the cell was suspended, appropriate aliquots of cell suspension were added to new cultures vessels. The cultures were incubated at $37^{\circ} \mathrm{C}$ for $24 \mathrm{hrs}$. Finally, after the cells treatment with serial concentrations of the compound to be stored using incubation for $48 \mathrm{hrs}$ at $37^{\circ} \mathrm{C}$, and then the plates were examined under an inverted microscope and proceed for the MTT assay The cultures were removed from the incubator into laminar flow hood, each vial of MTT [M5655] was reconstituted to be used with $3 \mathrm{ml}$ of medium (without phenol red \& serum) the reconstituted MTT was added in an amount equal to $10 \%$ of the culture medium volume the culture were incubated for 2-4hrs and then the cultures were removed. The resulted formazan crystal was removed by adding suitable amount of MTT solution (M-8910) equal to the original volume of culture medium. The gyratory shaker was used in mixing in order to enhance dissolution of the MTT formazan crystals. An appropriate type of plate reader was used or the contents of individual wells was transferred to appropriate size covets to be ready for measurement using the spectrophotometer absorbance at a wavelength of $690 \mathrm{~nm}$ the result was subtracted from $570 \mathrm{~nm}$ measurement. Determination of gene expression of all materials was done by using RT-PCR.

\section{Results}

The cytotoxicity $\left(\mathrm{IC}_{50}\right)$ of all materials increased as the processing time increased. The cytotoxicity of bee venom (BV) was 
$87.8,36.9 \& 9.7 \mu \mathrm{g} / \mathrm{ml}$ after 24 hours, 48 hours \& 72 hours incubation, respectively. But, $\mathrm{IC}_{50}$ of BV-PLA2 was 17.3 after 24 hours, 9.6, after 48 hours, \& 7.45 after 72 hours incubation. Finally, in the case of ribovinal it was 137.5 after 24 hours, 24.6 after 48 hours, and 31.6 after 72 hours. The cytopathic effect determined in vero cells under the effect of BV, BV-PLA2 and ribovinal as compared with control and groups infected by influenza virus and not treated. Both BV and BV-PLA2 showed low cytopathic effects compared with the effect of ribovinal as a commercial drug. Gene expression represented gene expressions of interferon- gamma (INFr) under the effect of BV, BV-PLA2 and ribovinal using RTPCR. BV \& ribovinal showed highly significant increase in INFr expression after $48 \mathrm{~h}$ incubation in direct (35.6) and indirect (46.0) effects of BV, besides, 38.9, \& 49.3 under the effect of ribovinal. But, BV-PLA2 showed an insignificant increase in both cases (14.8 \& 16.4) direct and indirect effects, respectively. Details were given in figures $(1,2 \& 3)$.

\section{Discussion}

Egypt, is a Mediterranean country, locates in the Northeast region of Africa, spanning about 1 million square kilometers and considered as one of the highest populous country in the Middle East and North Africa (100 million inhabitants) mostly living near the Nile banks. For about ten years, Egypt became an endemic region for pathogenic influenza virus (El-Shesheny et al, 2020). At least, the Crimean-Congo hemorrhagic fever (El Bahnasawy et al, 2012), the West Nile virus (El Bahnasawy et al, 2013a), Rift Valley fever (El Bahnasawy et al, 2013b), dengue fever (Morsy, 2018) Antiviral drugs are a separate set of drugs prescribed for the management of a number of diseases caused by viruses (Vardanyan and Hruby, 2006). Do not assume that all antiviral drugs can help to prevent the development of common cold. The general idea behind the design of modern antiviral drugs was to identify viral proteins or parts of these proteins that can be disabled. These "targets" in general should be different from any proteins or parts of human proteins, to reduce side effects. However, these proteins must be many strains of the virus, or even between different types of viruses belonging to one family, so that one drug has a widespread impact (Andersen et al, 2020). For example, a researcher may target an important enzyme, not the patient, to be involved in the strains of the virus, and then consider what can be done to stop it (Mifsud et al, 2019). Despite the importance of this set of drugs, it is considered as a child taking its first steps in terms of development and industry, most antiviral medications don't deliver a cure, yet rather permit control of the disease in addition to it has effected very few viruses, However, the limitations of antiviral treatment, including the high expenses in manufacturing these drugs, make the requirement for the counter-active action even increasingly pressing (De Clercq, 2004). This agreed with the present results of studying bee venom (BV) in vitro. But, the present result disagreed with Taky et al. (2017) who found that the decided $\mathrm{IC}_{50}$ characteristics were prepared inside the request of EBV $>$ PLA2 and the $\mathrm{IC}_{50}$ became $13.7 \& 25 \mathrm{gm} / \mathrm{ml}$. The tried items demonstrated the antiviral capability against DNA and RNA contamination models; HSV-1 \& RVFV with an improvement $10 \%$ \& $26.3 \%$ dilemma for PLA2 and EBV individually if there needed to stand up a prevalence of testing the direct impact of HSV-1.

In the present study, the inhibitory effect against to RVFV as a RNA contamination model of restraint changed into $7.7 \%$ \& $27 \%$ for EBV \& PLA2 respectively. Differences between both results might be due to difference in the incubation period. In the Rift Valley infection, bee venom and phospholipase gave low critical diminished $(\mathrm{P} \geq 0.05)$ in both immediate and circuitous strategy. This outcome uncovered that the two have the direct activity on RVF infection agreed with Hassan et al. (2015). The past outcome 
might be expected the immediate antiviral of melittin and phospholipase A2 on infection as observed (Kainulainen et al, 2016).

The honey bee venom acts as an antiviral restorative treatment either by fundamental or neighborhood application that it has enzymes and peptides influencing the infection. The antiviral impact of PLA2 depended basically on their capacity to hydrolyze phospholipids in host cell films. This study showed the same significant result about the antiviral effect of bee venom as previously established that discharged phospholipases A2 (sPLA2) from honey bee and snake venoms have an effective enemy of human immunodeficiency contamination (HIV) motion (Fenard et al, 2001). PLA2s square HIV1 passage into host cells through a tool linked to SPLA2 authoritative to cells.

In present study, 12 manufactured peptides were given from honey bee venom sPLA2 (PLA2) had been attempted for restraint of HIV-1 infection. This agreed with Choi et al. (2005). The p3bv peptide (amino acids 21 to 35 of bvPLA2) turned into found to restrain replication of $\mathrm{T}$-lymphotropic ( $\mathrm{T}$ tropic) HIV-1 separates (ID50 $=2 \mu \mathrm{M}$ ) yet became without impact on monocytotropic (M-tropic) HIV-1 secludes. The P3BV was located ready for heading off the cellularcellular mixture procedure interceded via $\mathrm{T}$ tropic HIV-1 envelope. At long ultimate, $\mathrm{p} 3 \mathrm{bv}$ can preclude the legitimate of the radiolabeled stromal cell-decided element (SDF)-1 $\alpha$, the ordinary ligand of CXCR4, and the authoritative of $12 \mathrm{G} 5$, an enemy of CXCR4 monoclonal counter acting agent. Taken together, these consequences display that $\mathrm{p} 3 \mathrm{bv}$ obstructs the replication of $\mathrm{T}$ tropic HIV-1 strain via interfacing with CXCR4. Its gadget of a hobby anyway appears specific from that of BV PLA2 in mild of the truth that the closing represses replication of each T-tropic \& M-tropic separates and did not contend with SDF-1 $\alpha$ \& 12G5 authoritative to CXCR4 (Fenard et al, 2001).

Cytopathic effect: virus was cytocidal and
Cytopathic effect: virus was cytocidal and attacked tissues demonstrate morphological changes frequently termed cytopathic results which included mobile rounding along with change with redistribution of cell membrane. Genital herpes as RNA virus also brought by chemical changes including inhibition of interpretation along with transcribing (RuizSáenz et al, 2009). The antiviral effect of PLA2 depends fundamentally on ability to hydrolyze phospholipids in host cell films. PLA2 controls HIV contamination (as RNA infection) neither from virucidal effect nor cytotoxic effect, occurred by neutralizing activity of intracellular landing of viral capsid, and interfere viral entry into host cells (Fenard et al, 1999). Akdis et al. (1998) found that honey bee venom phospholipase A2 (PLA) instigated high IL-4, IL-5 \& IL-13 generation infringe blood mononuclear cell societies. These highlights may empower new applications for more secure immunotherapy. This agreed with Ramadan et al. (2009) who assessed the virucidal activity of honey bee venom in opposition to RNA model virus of West Nile virus (WNV) revealed that there was a significant depletion rate of WNV infectivity titer post heat remedy brooding at $37^{\circ} \mathrm{C}$ for three, $6,24 \& 48 \mathrm{hrs}$ submit treatment with venom recording 5.1 $\log (10) / 0.1 \mathrm{ml}, 4.5 \log (10) / 0.1 \mathrm{ml}, 2.1 \log$ (10)/0.1 $\mathrm{ml}$ and $0.55 \mathrm{log}(10) / 0.1 \mathrm{ml}$ for in part. The antiviral movement of honey bee venom of HSV-1 as a DNA model infection confirmed that there has been a non-noteworthy abatement in the infectivity titer that publishes warm treatment. In the same time, the antiviral motion of honey bee venom towards Adeno infection serotype 7 exposed that there was a non-essential abatement in Adeno 7 titer 3, 6 \& 24 hours submit hatching at $37^{\circ} \mathrm{C}$. Likewise, evaluation of antiviral movement of honey bee venom in opposition to RNA version contamination West There was a non-noteworthy lessening in West Nile Virus titer after brooding time of 3,6 and 24 hours post remedy at $37^{\circ} \mathrm{C}$. The antiviral action of honey bee venom 
became likewise contrasted with the same antiviral drug; Interferon-2an (IFN-2a). HSV-1 became irrelevantly faded account $5.5 \log (10) / 0.1 \mathrm{ml}$ inside the honey bee venom treated cells contrasted with large discount whilst treated with (IFN-2a) recording $3.2 \log (10) / 0.1 \mathrm{ml}$. In the sametime, the antiviral action in opposition to adenovirus-7 recorded a huge reduction in contamination infectivity titer recording $3.4 \log (10) / 0.1 \mathrm{ml}$ submit honey bee venom contrasted and $3.25 \log (10) / 0.1 \mathrm{ml}$ post IFN treatment which implies that the in vitro investigations of the effect of standard IFN applied become equal to honey bee venom on the Adeno-7 infection. The RNA version infection; WNV become all around affected by honey bee venom than IFN where infection infectivity titer recorded $1 \log (10) / 0.1 \mathrm{ml}$ after honey bee venom treatment contrasted and $2.5 \mathrm{log}$ (10) $/ 0.1 \mathrm{ml}$ contamination infectivity titer post IFN treatment. The different results obtained may be because of different viruses used in the two studies. This agreed with Uddin et al. (2016) who reported that coincubation of non-cytotoxic quantities of BV and MLT, the principle element of BV, drastically inhibited the replication of enveloped viruses consisting of influenza an endemic (PR8), vesicular stomatitis virus (VSV), respiration syncytial virus (RSV), and Herpes simplex virus (HSV). Besides, the BV \& MLT inhibited the replication of nonenveloped viruses consisted of Enterovirusseventy-one (EV-71) and Coxsackie virus (H3). Such antiviral properties were mainly defined with the aid of virucidal mechanism. Besides, MLT covered mice that were challenged with lethal doses of pathogenic influenza A H1N1 viruses. Therefore, those effects offer the proof that BV and MLT can be a capability source as a promising antiviral agent, mainly to broaden as the vast spectrum antiviral agent. This was approved that BV \& MLT derived from BV exhibited effective antiviral hobby in opposition to numerous enveloped and non-enveloped viruses in vitro and Influenza virus inside the in vivo mouse version. Also, its antiviral mechanism was confirmed to involve direct interaction with the viral surface.

Apart from BV virucidal interest, BV can stimulate kind I IFN, which sooner or later ought to stimulate the antiviral country within the host cellular and also inhibit the viral replication. Taken collectively, the outcomes advise that BV or MLT has capability to be prophylactic or therapeutic agents for the infectious viral diseases.

Generally, the bee venom is a weapon that bees use to protect themselves against their enemies mainly man, and since the ancient times dates back to Hippocrates, and references to the treatment was found in ancient Egyptian and Greek Medical Writings as well as the skin aging application of honeybee venom (BV) was practiced and persisted until nowadays ( Han et al, 2013).

Lui et al, (1995) reported that bee venom immunotherapy has dual benefits: patients were protected from subsequent sting anaphylaxis and there was reduced psychological morbidity. But, to be effective, venom immunotherapy requires a prolonged period of carefully treatment and each venom injection caused local and systemic side effects. Genetic factors were present in patients who develop direct hypersensitivity to stings.

In humans, however, it has been used as an anti-inflammatory medicine to relieve pain and treat chronic inflammatory diseases such as rheumatoid arthritis and multiple sclerosis (Senel et al, 2014). The use of bee venom as a therapeutic agent for the relief of joint pains Also, as apitherapy, the technique was widely used in Eastern Europe, Asia, and South America. The beneficial effects of bee stings can be attributed to mellitinin, an antiinflammatory agent, hundred times active than cortisone (Alqutub et al, 2011). While bee venom itself causes nociceptive and neurotoxic effects, several studies proved that its venom have a radio protective (Gajski and Garaj-Vrhovac, 2009), anti-mutagenic (Varanda et al, 1999), anti-inflammatory (Choi et al, 2012; Kim et al, 2013; Park 
et al, 2014), anti-nociceptive (Baek et al, 2006; Lim et al, 2013; Yoon et al, 2015) and anticancer (Orsolic et al, 2003a,b; Moon et al, 2006; Huh et al, 2009) activities. Bee venom was given in the form of a direct bee sting or else by injection of a venom extract. The treatment is usually given twice a week. Some reports have shown beneficial effects of bee venom in post herpetic neuralgia (Jani et al, 2007), swine flu (Singla and Bhat, 2010), fibromyalgia, multiple sclerosis and others (Janik et al, 2007). Besides, Leandro et al. (2015) in Brazil found that BV was successfully used as antibacterial, antifungal and antiviral agent. Tawfik (2018) in Egypt reported that bee venom in hydatidosis not only affected the cellular structure of protoscolices but, also triggered apoptosis. Also, An et al. (2018) in Korea suggested that bee venom and melittin would be suitable for epicutaneous application, as topical administration was often appropriate for treatment of atopic dermatitis. Wehbe et al. (2019) in Lebanon reported that the several active molecules in bee venom such as peptides and enzymes that have advantageous potential in central nervous system diseases, such as Parkinson's disease, Alzheimer's disease, and amyotrophic lateral sclerosis

Moreover, the non-alcoholic fatty liver diseases (NAFLD) encompassed a spectrum of liver abnormalities, ranged from simple steatosis to steatohepatitis (non-alcoholic steatohepatitis; NASH) and fibrosis that may progress to cirrhosis and possibly hepatocarcinoma. NAFLD was associated with insulin resistance, obesity, diabetes mellitus, hyperlipidemia, visceral adiposity and other cardio metabolic alterations (Neuschwander-Tetri and Caldwell, 2003). Hanafi et al. (2018) represented an advance in biomedical science because it showed the antioxidant potential of BV treatment and its normalization effect on adipocytokines that made it a tempting therapeutic agent for NAFLD. But, unfortunately, the bee stings caused severe reactions and have caused many victims in the last years. Allergic reactions can be trig- gered by a single sting and the greater the number of stings, the worse the prognosis. The poisoning effects can be systemic and can eventually cause death. The poison components were melitin, apamin, peptide 401, phospholipase A2, hyaluronidase, histamine, dopamine, and norepinephrine, with melitin being the main lethal component. Acute kidney injury (AKI) was observed in the patients suffered from the bee stings that was due to multiple factors, such as the intravascular hemolysis, rhabdomyolysis, hypotension and direct toxicity of venom components to the renal tubules. The arterial hypotension played the important role in this type of AKI, and led to the ischemic renal lesion (Silva et al, 2017). They concluded that the severity of AKI was associated with the stings number, since creatinine levels were higher, in most cases, when there were more than 1,000 stings. But, Cherniack and Govorushko (2018) in USA bee venom consists of multiple anti-inflammatory compounds such as melittin, adolapin, apamin, and phospholipase A2 could be anti-inflammatory in low concentrations and pro-inflammatory in others. The venom contained pro-inflammatory substances, melittin, mast cell degranulation on peptide 401, and histamine. They added that in small studies, bee venom acupuncture was used in man to successfully treat a number of musculor-skeletal diseases such as lumbar disc disease, osteoarthritis of knee, rheumatoid arthritis, adhesive capsulitis, and lateral epicondylitis. Bee venom acupuncture can also alleviate neurological diseases, as peripheral neuropathies, stroke, Parkinson's disease, and such treatment was even piloted in one series to alleviate depression. They concluded that bee venom caused anaphylaxis, and even deaths in patients who successfully received the therapy prior to the adverse event. While the incidence of adverse events was unknown, the number of published reports of toxicity is small. Refining the bee venom to remove harmful substances may potentially limit its toxicity. 


\section{Conclusion}

The outcome data showed that bee venom (BV) and ribovinal have antiviral effects mainly by direct effect, while BV-pLA2 has mainly indirect antiviral effect against the influenza virus. Bee venom and ribovinal have antiviral effect mainly direct while pLA2 have mainly indirect antiviral effect against influenza virus.

Bee venom therapy is the specialized form of apitherapy, and required the expertise of a well-trained physician. Usually, a course of treatment starts with testing the patient for the bee venom allergy, which is known to occur in $1 \%$ of the general population

\section{Recommendations}

The utilizing honey bee venom (BV) and BV-PLA2 as the infusion or the topical application as elective drugs in veterinary and human practice as it is sheltered and viable medicine against infectious disease of RNA.

In this way, the antiviral concentrating action of past tried material in creature model (in vivo) was prescribed.

\section{References}

Alqutub, AN, Masoodi, I, Alsayari, K, Alomair, A, 2011: Bee sting therapy-induced hepatotoxiccity: A case report. World J. Hepatol. 3, 10: 268-70.

Akdis, CA, Blesken, T, Akdis, M, Wüthrich, B, Blaser, K, 1998: Role of interleukin 10 in specific immunotherapy. J. Clin. Investig.102, 1: 98-106.

An, HJ, Kim, JY, Kim, WH, Gwon, MG, Gu, HM, et al, 2018: Therapeutic effects of bee venom and its major component, melittin, on atopic dermatitis in vivo and in vitro. Br. J. Pharmacol. 175, 23:4310-24

Andersen, PI, Ianevski, A, Lysvand, H, Vitkauskiene, A, Oksenych, $\mathrm{V}$, et al, 2020: Discovery and development of safe-in-man broad-spectrum antiviral agents, Int. J. Infect. Dis.93:276-68.

Baek, YH, Huh, JE, Lee, JD, Choi, DY, Park, DS, 2006: Antinociceptive effect and the mechanism of bee venom acupuncture (apipuncture) on inflammatory pain in the rat model of collag- eninduced arthritis: Mediation by $\alpha_{2}$-adrenoceptors. Brain Res. 2006; 1073-1074:305-310.

Blank, S, Etzold, S, Darsow, U, Schiener, M, Eberlein, B, et al, 2017: Component-resolved evaluation of the content of major allergens in therapeutic extracts for specific immunotherapy of honeybee venom allergy. Hum. Vaccin. Immunother. 13, 10:2482-9.

Blut, A, 2009: Influenza virus. Transfus. Med. Hemothe 36, 1:32-6.

Carman, K, Calik, M, Karal, Y, Isikay, S, Kocak, O, et al, 2019: Viral etiological causes of febrile seizures for respiratory pathogens (EFES Study). Hum. Vaccin. Immunother. 15, 2:496502.

CDC, 2019: National Center for Immunization and Respiratory Diseases (NCIRD).

Cherniack, EP, Govorushko, S, 2018:To bee or not to bee: The potential efficacy and safety of bee venom acupuncture in humans. Toxicon. 154:74-8.

Choi, WT, Tian, S, Dong, CZ, Kumar, S, Liu, $\mathrm{D}$, et al, 2005: Unique ligand binding sites on CXCR4 probed by a chemical biology approach: Implications for the design of selective human immunodeficiency virus type-1 inhibitors. Virol. 79, 24:15398-404

Choi, MS, Park, S, Choi, T, Lee, G, Haam, K $\mathrm{K}$, et al, 2012: Bee venom ameliorates ovalbumin induced allergic asthma via modulating $\mathrm{CD}^{+}$ $\mathrm{CD} 25^{+}$regulatory $\mathrm{t}$ cells in mice. Cytokine 61 : 256-65.

De Clercq, E, 2004: Antiviral drugs in current clinical use. J. Clin. Virol. 30, 2:115-33.

El-Bahnasawy, MM, Sabah, AAA, Saleh, HA A, Morsy, TA, 2012: The tick-borne CrimeanCongo hemorrhagic fever in Africa, Asia, Europe, and America: What about Egypt? J. Egypt. Soc. Parrasitol. 42, 2:373-84.

El-Bahnasawy, MM, Megahed, LA, Saleh, H AA, Morsy, TA, 2013a: The Rift Valley fever: Could re-emerge in Egypt again? J. Egypt. Soc. Parasitol. 43, 1:41-56.

El-Bahnasawy, MM, Khater, MMKh, Morsy, TA, 2013b: The mosquito borne west Nile virus infection: Is it threating to Egypt or a neglected endemic disease? J. Egypt. Soc. Parasitol. 43, 1: 87-102

El-Shesheny, R, Kandeil, A, Mostafa, A, Ali, MA, Webby, RJ, 2020: H5 influenza viruses in Egypt. Copyright (C) 2020 Cold Spring Harbor Laboratory Press; all rights reserved. Correspondence: richard.webby@stjude.org

Fenard, D, Lambeau, G, Maurin, T, Lefebvre, JC, Doglio, A, 2001: A peptide derived from bee venom-secreted phospholipase A2 inhibits replication of T-cell tropic HIV-1 strains via int- 
eraction with the CXCR4 chemokine receptor. Mol. Pharmacol. 60, 2:341-7.

Gajski, G, Garaj-Vrhovac, V, 2009: Radioprotective effects of honeybee venom (Apis mellifera) against 915-MHZ microwave radiationinduced DNA damage in wistar rat lymphocytees: In vitro study. Int. J. Toxicol. 28:88-98.

Han, SM, Park, KK, Nicholls, YM, Macfarlane, N, Duncan, G, 2013: Effects of honeybee (Apis mellifera) venom on keratinocyte migration in vitro. Pharmacogn. Mag. 9, 35:220-6.

Hassan, MI, Mohamed, AF, Amer, MA, Hammad, KM, Riad, SA, 2015: Monitoring of the antiviral potential of bee venom and wax extracts against Adeno-7 (DNA) and Rift Valley fever virus (RNA) viruses models. J. Egypt. Soc. Parasitol. 45, 1:193-8.

Hanafi, MY, Zaher, ELM, El-Adely, SEM, Sakr, A, Ghobashi, AH, et al, 2018: The therapeutic effects of bee venom on some metabolic and antioxidant parameters associated with HFD -induced non-alcoholic fatty liver in rats. Exp. Ther. Med. 15, 6:5091-9.

Hidalgo, J, Woc-Colburn, L, 2020: Influenza, Measles, SARS, MERS, and Smallpox Highly Infectious Diseases in Critical Care. Jan $3: 69$ 96 doi: 10.1007/978-3-030-33803-9-5

Huh, JE, Baek, YH, Lee, MH, Choi, DY, Park, DS, et al, 2010: Bee venom inhibits tumor angiogenesis and metastasis by inhibiting tyrosine phosphorylation of VEGFR-2 in LLC-tumor-bearing mice. Canc. Lett. 292:98-110.

Janik, JE, Wania, GL, Kalauokalani, DK, 2007: Bee stings-a remedy for postherpetic neur algia? a case report. Reg. Anesth. Pain Med. 32: 533-5.

Kainulainen, M, Lau, S, Samuel, CE, Hornung, V, Weber, F, 2016: NSs virulence factor of rift valley fever virus engages the f-box proteins FBXW11 and $\beta$-TRCP1 to degrade the antiviral protein kinase PKR. J. Virol. 90, 13: 6140-7.

Kim, H, Lee, G, Park, S, Chung, HS, Lee, H, et al, 2013: Bee venom mitigates cisplatin-induced nephrotoxicity by regulating $\mathrm{CD} 4{ }^{+} \mathrm{CD} 25^{+}$ Foxp $3^{+}$regulatory $\mathrm{T}$ cells in mic. Evid. Based Complement Alternat. Med. 2013 doi: 10. 1155/ 2013/879845.

Leandro, LF, Mendes, CA, Casemiro, LA, Vinholis, AH, Cunha, WR, et al, 2015: Antimicrobial activity of apitoxin, melittin and phospholipase A2 of honey bee (Apis mellifera) venom against oral pathogens. Ana. Acad. Brasil. Ciên. 87, 1:147-55.
Lim, BS, Moon, HJ, Li, DX, Gil, M, Min, JK, et al, 2013: Effect of bee venom acupuncture on oxaliplatin-induced cold allodynia in rats. Evid. Based Complement. Alternat. Med. 2013; doi: 10.1155/2013/369324.

Lui, CL, Heddle, RJ, Kupa, A, Coates, T, Roberts-Thomson, P J, 1995: Bee venom hypersensi-tivity and its management: patients perception of venom desensitisation. Asian Pac J Allergy Immunol 13, 2:95-100.

Mifsud, EJ, Hayden, FG, Hurt, AC, 2019: Antivirals targeting the polymerase complex of influenza viruses. Antiviral Res.169: 104545.

Moon, DO, Park, SY, Heo, MS, Kim, KC, Park, C, et al, 2006: Key regulators in bee venom-induced apoptosis are $\mathrm{Bcl}-2$ and caspase3 in human leukemic U937 cells through downregulation of ERK and Akt. Int. Immunopharmacol. 6:1796-807.

Morsy, TA, 2018: Aedes aegypti and dengue virus infections. J. Egypt. Soc. Parasitol. 48, 1: 183-96.

Neuschwander-Tetri BA, Caldwell, SH, 2003: Nonalcoholic steatohepatitis: Summary of an AASLD single topic conference. Hepatology 37:1202-19.

Orsolic, N, Knezevic, A, Sver, L, Terzic, S, Hackenberger, Bk, 2003b: Influence of honey bee products on transplantable murine tumours. Vet. Complement. Oncol. 1:216-26.

Orsolic, N, Sver, L, Verstovsek, S, Terzic, S, 2003a: Inhibition of mammary carcinoma cell proliferation in vitro and tumor growth in vivo by bee venom. Toxicon 41:861-70.

Park, YC, Koh, PS, Seo, BK, Lee, JW, Cho, NS, et al, 2014: Long-term effectiveness of bee venom acupuncture and physiotherapy in the treatment of adhesive capsulitis: A one-year follow-up analysis of a previous randomized controlled trial. J. Altern. Complement. Med. 20: 919-24.

Ramadan, RH, Mohamed, AF, Abd El-Daim, MS, 2009: Evaluation of antiviral activity of honeybee venom on DNA and RNA virus models. Egypt. Acad. J. Biol. Sci. 2, 1:247-58.

Ruiz-Sáenz, J, Goez, Y, Tabares, W, LópezHerrera, A, 2009: Cellular receptors for foot and mouth disease virus. Intervirology 52, 4: 201-12.

Sehatzadeh S, 2012: Influenza and pneumococcal vaccinations for patients with chronic obstructive pulmonary disease (COPD): An evidence- 
based review. Ont. Hlth. Technol. Assess Ser. 12, 3:1-64

Senel, E., Kuyucu, M, Suslu, I, 2014: Honey and bee venom in dermatology: A novel possible alternative or complimentary therapy for psoriasis vulgaris. Anc. Sci. Life33:192-3.

Singla, RK, Bhat, VG, 2010: Honey bee sting and venom offering active as well as passive immunization could reduce swine flu pandemic A (H1N1) Med. Hypotheses 74:617-61.

Silva, GBD Junior, Vasconcelos, AG Junior, Rocha, AMT, Vasconcelos, VR, Neto, JB, et al, 2017: Acute kidney injury complicating bee stings, a review. Rev. Inst. Med. Trop. Sao Paulo 59:e25. doi: 10.1590/S1678-9946201759 025 Taky, SS, Bakkar, A, Fahmy, A, Elfiky, AA, 2017: Evaluation of Antiviral Activity of Bee Venom, Phospholipase A-2 (PLA-2) and Propolis against DNA and RNA Virus Models: In-vitro study. Mol. Pharmacol. 2:1-8.

Tawfik, RA, 2018: In vitro scolicidal effect of bee venom on Echinococcus granulosus protoscolices. J. Egypt. Soc. Parasitol. 48, 3: 689-97

Toledo-Rueda, W, Rosas-Murrieta, NH, Muñoz-Medina, JE, González-Bonilla, CR, Rey-

\section{Explanation of figures}

Fig. 1: $\mathrm{IC}_{50}$ of BV, PLA2 and Ribovinal with time.

Fig. 2: Cytopathic effect of BV, PLA2 and Ribovinal with time.

Fig. 3: Direct and indirect expression of BV, BV-PLA and ribovinal

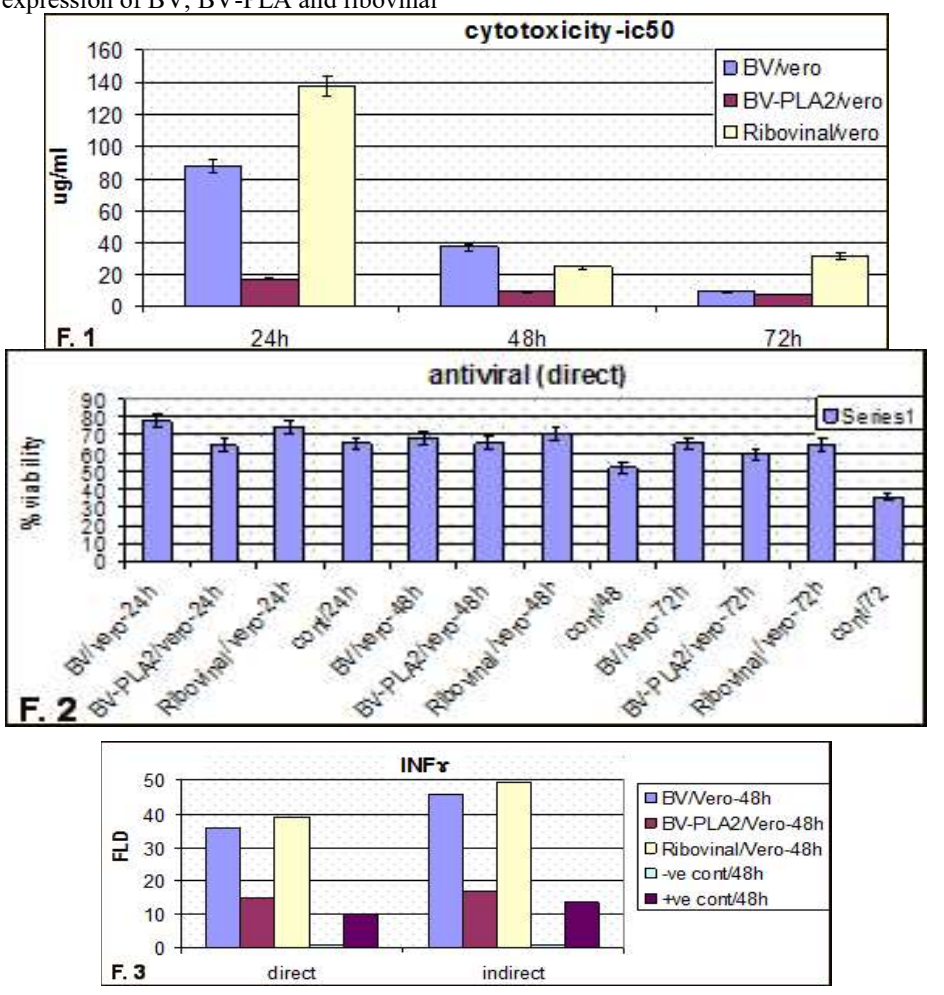

